\title{
Evaluating the Marginal Land Resources Suitable for Developing Bioenergy in Asia
}

\author{
Jingying Fu, ${ }^{1,2}$ Dong Jiang, ${ }^{1}$ Yaohuan Huang, ${ }^{1}$ Dafang Zhuang, ${ }^{1}$ and Wei Ji ${ }^{1,2}$ \\ ${ }^{1}$ State Key Laboratory of Resources and Environmental Information Systems, \\ Institute of Geographical Sciences and Natural Resources Research, Chinese Academy of Sciences, Beijing 100101, China \\ ${ }^{2}$ University of Chinese Academy of Sciences, Beijing 100049, China
}

Correspondence should be addressed to Dong Jiang; jiangd@igsnrr.ac.cn

Received 23 October 2013; Revised 11 December 2013; Accepted 10 January 2014; Published 13 March 2014

Academic Editor: Shengli Huang

Copyright (C) 2014 Jingying Fu et al. This is an open access article distributed under the Creative Commons Attribution License, which permits unrestricted use, distribution, and reproduction in any medium, provided the original work is properly cited.

\begin{abstract}
Bioenergy from energy plants is an alternative fuel that is expected to play an increasing role in fulfilling future world energy demands. Because cultivated land resources are fairly limited, bioenergy development may rely on the exploitation of marginal land. This study focused on the assessment of marginal land resources and biofuel potential in Asia. A multiple factor analysis method was used to identify marginal land for bioenergy development in Asia using multiple datasets including remote sensingderived land cover, meteorological data, soil data, and characteristics of energy plants and Geographic Information System (GIS) techniques. A combined planting zonation strategy was proposed, which targeted three species of energy plants, including Pistacia chinensis (P. chinensis), Jatropha curcas L. (JCL), and Cassava. The marginal land with potential for planting these types of energy plants was identified for each $1 \mathrm{~km}^{2}$ pixel across Asia. The results indicated that the areas with marginal land suitable for Cassava, P. chinensis, and JCL were established to be 1.12 million, 2.41 million, and 0.237 million $\mathrm{km}^{2}$, respectively. Shrub land, sparse forest, and grassland are the major classifications of exploitable land. The spatial distribution of the analysis and suggestions for regional planning of bioenergy are also discussed.
\end{abstract}

\section{Introduction}

The world is facing problems related to finite availability of fossil fuels, the high price of petroleum, and the environmental impacts caused by the use of traditional fuels. The energy consumption of the world increased from 77,245 thousand barrels per day in 2001 to 88,034 thousand barrels per day in 2011. Asia Pacific accounted for $32 \%$ of the total world energy consumption [1]. This increase in energy demand is depleting fossil energy reserves at a high rate. In addition, the use of fossil fuels has caused many environmental problems, such as greenhouse gas (GHG) emissions. Therefore, energy security and climate change mitigation are two main drivers that have pushed renewable energy production to the top of the global agenda [2].

Bioenergy, the most abundant and versatile type of renewable energy, has recently attracted worldwide attention [3]. Biofuels are environmentally friendly and carbon neutral and can play a prominent role in the energy portfolio [4].
The production of liquid biofuels can reduce GHG emissions by $12 \%-115 \%$ compared to traditional fossil fuels. GHG emissions are reduced $12 \%$ by the production and combustion of ethanol and $41 \%$ by biodiesel according to Hill et al. [5]. Adler et al. found that ethanol and biodiesel reduced GHG emissions by approximately $40 \%$ when derived from corn, by approximately $85 \%$ when from reed canary grass, and by approximately $115 \%$ when from hybrid switch grass and poplar [6]. The global warming potential (GWP, in $\mathrm{kg}$ $\mathrm{CO}_{2}$-equivalent) of the production of biodiesel in the UK was calculated Stephenson et al. The results showed that large-scale production of biodiesel saved $26 \%$ of the GWP and small-scale production saved $32 \%$ of the GWP when compared to ultralow sulphur diesel [7].

The present global biomass demand for energy purposes is estimated to be 53 Quintillion joules [8]. Overall, global energy demand will grow $35 \%$, even with significant efficiency gains. Energy demand in developing nations will rise 65 percent by 2040 (compared to 2010) as a result of 
expanding economies and growing populations. According to the new public energy outlook, 75 percent of the world's population will reside in Asia Pacific and Africa by 2040. India will have the largest population after 2030 [9]. A wide range of indicators suggest that dramatic developments are taking place in Asian energy markets [10], and large-scale bioenergy development is extremely urgent.

Recently, a number of studies have assessed the potential of biofuel. Kumar et al. assessed ethanol and biodiesel development in Thailand in terms of feedstock, production, planned targets, policies, and sustainability (environmental, socioeconomic, and food security aspects) [11]. An assessment of bioenergy potential was also carried out in England, the Midwest United States, China, and other countries [1215]. The environmental life cycle assessment of lignocellulosic conversion to ethanol was reviewed by Borrion et al. Numerous studies of lignocellulosic ethanol fuel generated significantly different results due to differences in data, methodologies, and local geographic conditions [16]. In addition to feedstock, energy benefits, and GHG reductions, issues related to land resources and food security are an important consideration for Asia-scaled applications.

Schröder et al. considered bioenergy development as an effective way to save the world from an energy crisis. They illustrated the ability to produce novel energy plants for growth on abandoned land [17]. Liu et al. analyzed the bioenergy production potential on marginal land in Canada. The results showed that approximately 9.48 million hectares could be identified as available marginal land in Canada. If this land was fully utilized for growing energy crops, the production of biofuel would be 33 million tons (using switch grass) or 380 million tons (using hybrid poplar). Batidzirai et al. reviewed the current, state-of-the-art approaches and methodologies used in bioenergy assessments and identified key elements that are critical determinants of bioenergy potentials. Bioenergy potential assessments in the US, China, India, Indonesia, and Mozambique were also presented in the paper [18]. Hattori and Morita [19] studied which energy crops can be used for sustainable bioethanol production and where they can be grown. They found that, in Japan and other Asian countries, rice can be grown as an energy crop in unused low-land paddy fields. Bioenergy development in China has also been studied, especially the potential energy production on marginal land in the context of food security $[3,20-22]$. The biomass plant Jatropha curcas L. (JCL) was shown to be a better economic, environmental, and land preservation alternative to corn or millet planted in the poor, gravel soil. and drought land in Taitung, Taiwan [23].

However, the bioenergy development in the abovementioned studies and most other current research is studied on a regional scale. A potential bioenergy view of the entirety of Asia is not available. The main objective of this study is to present a comprehensive assessment on the marginal land resources which are suitable for developing bioenergy in Asia, without affecting food and ecoenvironmental security. Asia is the world's largest and most populous continent. It is facing significant pressure for food production. To avoid using the limited amount of arable land, adaptable energy plants that can be grown on marginal land and at scale must be used. Cassava, P. chinensis, and JCL have been widely proven in existing literature and are further studied in this paper [14, 24-34]. P. chinensis and JCL are nonfood plants. Cassava is used as a food plant in some places. However, we only analyzed its development potential in uncultivated areas (marginal land).

Cassava and JCL are classified as second-generation biofuel feedstock, which are derived from crop residues, energy plants, and construction waste [35]. They can reduce GHG emissions and energy dependency during the life cycle when compared to the fossil fuel. The most important advantage of second-generation biofuels is that they will ensure the security of food supply compared with firstgeneration biofuels which are produced from food-based crops. They are sustainable and environmentally friendly [36]. Bioethanol is produced by hydrolysis and fermentation of carbohydrate feedstock. This type of energy plant usually has high saccharide, starch, and fiber content. Cassava which has been widely studied is this kind of plant. Biodiesel is produced from oil plants such as JCL. The oil extracted is blended with diesel to produce fuel [34, 37-47].

To achieve our goal, we used Geographic Information System (GIS) technology to identify the spatial distribution of marginal lands which are suitable for bioenergy development. The datasets of growth habits of energy plants, remote sensing-derived land cover, terrain, meteorological data, and soil data were processed to $1 \mathrm{~km}^{2}$ grid across Asia.

\section{Methodology}

Four steps were implemented for this study. First, we identified the marginal land resources suitable for developing bioenergy in Asia. Second, we chose the three aforementioned energy plants that have been proven as biofuels. Third, we reviewed the environmental requirements of each energy plant including preferred meteorological conditions, soil, and terrain. Finally, a multiple factor analysis method was used to evaluate the bioenergy development potential based on the availability of marginal land resources and the growing conditions of the energy plants within the data grid. This analysis was performed using ArcMap software. The specific procedures are presented in Figure 1.

2.1. Data Acquisition. In this study, the land cover, terrain (including elevation and slope), meteorological conditions (including precipitation and temperature), and soil data (including soil organic matter content, soil depth, and soil texture) were used. The data sources and spatial resolutions are listed in Table 1. All the data in this study was resampled to cover the entirety of Asia at a $1 \mathrm{~km}^{2}$ resolution.

2.1.1. Land Cover. Land resources defined as marginal must also include land that is considered economically marginal. Therefore, we spatially define marginal land resources based on the land cover classification of unused land. The land cover dataset can be obtained from the GlobCover project. There are 23 land cover types in the dataset. This is the fundamental 


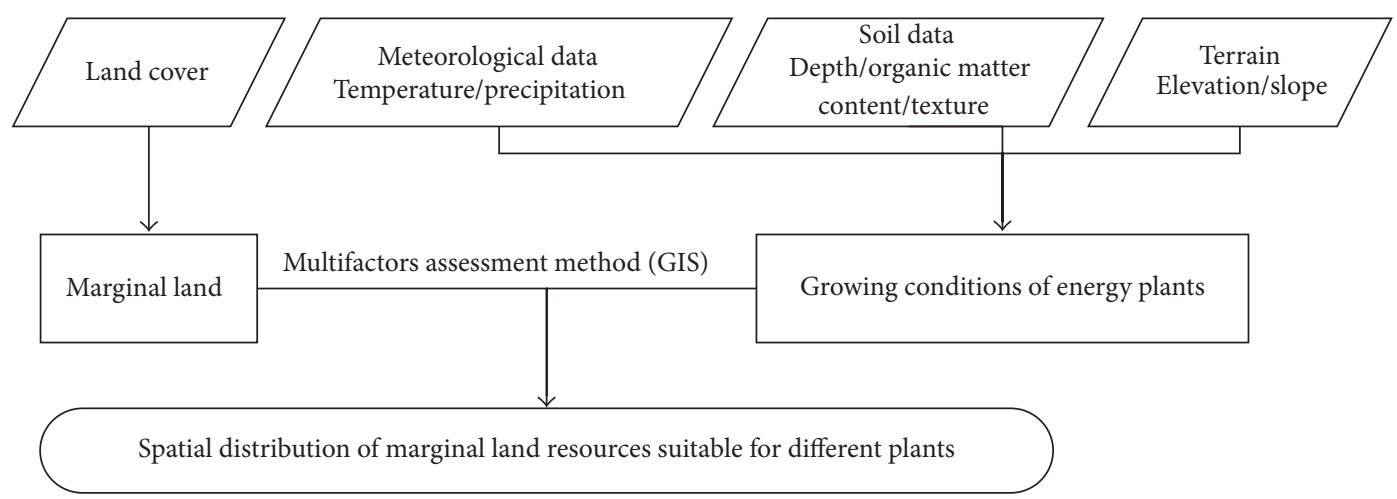

FIGURE 1: Evaluation of spatial distribution and suitability of marginal land resources for energy plants.

TABLE 1: Input data for identification of marginal land resources.

\begin{tabular}{lcr}
\hline Input data & Data sources & Original spatial resolution \\
\hline Land cover & ESA 2010 and UCLouvain [48] & $1 \mathrm{~km}$ \\
Terrain & & $90 \mathrm{~m}$ \\
$\quad$ Elevation & SRTM [49] & $90 \mathrm{~m}$ \\
$\quad$ Slope & & 30 arc-seconds $(\sim 1 \mathrm{~km})$ \\
Meteorological data & WorldClim [50] & 30 arc-seconds $(\sim 1 \mathrm{~km})$ \\
$\quad$ Precipitation & & 30 arc-seconds $(\sim 1 \mathrm{~km})$ \\
$\quad$ Temperature & & 30 arc-seconds $(\sim 1 \mathrm{~km})$ \\
Soil data & FAO/IIASA/ISRIC/ISS-CAS/JRC $[51]$ & 30 arc-seconds $(\sim 1 \mathrm{~km})$ \\
$\quad$ & & \\
$\quad$ Organic matter content & & \\
$\quad$ Soil depth & & \\
\hline
\end{tabular}

dataset for identification of marginal land that is suitable for bioenergy development.

2.1.2. Terrain. The CGIAR-CSI GeoPortal provides SRTM $90 \mathrm{~m}$ digital elevation data for the entire world [49]. The digital elevation models (DEMs) of Asia were extracted from the dataset above, and the slope was calculated using the spatial analysis tool in ArcMap. Thresholds for DEMs and slope, based on the growth habits of each energy plant, were determined (see Section 2.2).

2.1.3. Meteorological Data. WorldClim is a set of global climate layers (climate grids) with a spatial resolution of 30 arc-seconds (often referred to as $1 \mathrm{~km}$ resolution). The precipitation and temperature data used in this study were interpolated from observed data from 1950 to 2000 [50]. These two elements are very important for identifying suitable land. The requirement of each energy plant was identified (see Section 2.3).

2.1.4. Soil Data. The Harmonized World Soil Database (HWSD) contributes sound scientific knowledge for planning sustainable expansion of agricultural production and for guiding policies to address emerging land competition issues concerning food production, bioenergy demand, and threats to biodiversity. A resolution of approximately $1 \mathrm{~km}$ was selected to analyze agroecological zoning, food security, and climate change impacts. Soil attribute data were linked with GIS so that specific parameters could be displayed, characterized, and analyzed. These parameters include soil units, organic carbon, $\mathrm{pH}$, water storage capacity, soil depth, cation exchange, clay fraction, total exchangeable nutrients, lime and gypsum contents, sodium exchange percentage, salinity, textural class, and granulometry [51]. Soil texture, organic carbon content, and depth are key factors for growing energy plants.

2.2. Identification of Marginal Land. Marginal land has various meanings in different disciplines and, therefore, the spatial coverage of marginal land differs. Generally, marginal land is evaluated in terms of a cost-benefit analysis and is determined to be economically marginal [3]. Zhuang et al. established a marginal land evaluation system based on the definition of the Ministry of Agriculture (MoA) of China, a qualitative analysis of energy plants in different parts of China, expert suggestions on local planting of energy plants, land resources, and ecology, and other factors [22]. According to the definition of marginal land by MoA of China, marginal land is winter-fallowed paddy land and wasteland that may be used to cultivate energy crops. We only considered the wasteland in this study. Wasteland includes natural grassland, sparse forestland, scrubland, and 
TABLE 2: Growing conditions of energy plants.

\begin{tabular}{|c|c|c|c|c|c|c|}
\hline \multirow{2}{*}{ Growing conditions } & \multicolumn{2}{|c|}{ Cassava [24] } & \multicolumn{2}{|c|}{ P. chinensis $[52,53]$} & \multicolumn{2}{|c|}{$J C L[54-56]$} \\
\hline & Suitable & $\begin{array}{c}\text { Moderately } \\
\text { suitable }\end{array}$ & Suitable & $\begin{array}{c}\text { Moderately } \\
\text { suitable }\end{array}$ & Suitable & $\begin{array}{c}\text { Moderately } \\
\text { suitable }\end{array}$ \\
\hline \multicolumn{7}{|l|}{ Meteorological data } \\
\hline Annual average temperature $/{ }^{\circ} \mathrm{C}$ & $21 \sim 29$ & $18 \sim 21$ & $10 \sim 15.3$ & $\begin{array}{l}5.8 \sim 10 \text { or } \\
15.3 \sim 28.4\end{array}$ & $20 \sim 25$ & $17 \sim 20$ \\
\hline Average annual extreme lowest temperature $/{ }^{\circ} \mathrm{C}$ & - & - & $\geq-15$ & $-26.5 \sim-15$ & $\geq 2$ & $0 \sim 2$ \\
\hline Accumulated temperature of $10 /{ }^{\circ} \mathrm{C} \cdot \mathrm{d}$ & - & - & $\geq 3800$ & $1180 \sim 3800$ & - & - \\
\hline Precipitation $/ \mathrm{mm}$ & $1000 \sim 2000$ & $\begin{array}{l}600 \sim 1000 \text { or } \\
2000 \sim 6000\end{array}$ & $400 \sim 1300$ & $1300 \sim 1900$ & $600 \sim 1000$ & $\begin{array}{c}300 \sim 600 \text { or } \\
1000 \sim 1300\end{array}$ \\
\hline \multicolumn{7}{|l|}{ Soil data [51] } \\
\hline Soil depth/cm & $\geq 75$ & 30 75 & $\geq 60$ & $30 \sim 60$ & $\geq 75$ & $30 \sim 75$ \\
\hline Soil organic matter content $/ \%$ & $\geq 3.5$ & $1.5 \sim 3.5$ & - & - & $\geq 3.5$ & $1.5 \sim 3.5$ \\
\hline Soil texture/classes & 1 & 2 & - & - & 1 & 2 \\
\hline \multicolumn{7}{|l|}{ Terrain } \\
\hline Elevation/m & $\leq 1500$ & $1500 \sim 2000$ & - & - & $\leq 500$ & $500 \sim 1600$ \\
\hline Slope $/^{\circ}$ & $\leq 15$ & $15 \sim 25$ & $\leq 15$ & $15 \sim 25$ & $\leq 15$ & $15 \sim 25$ \\
\hline
\end{tabular}

unused land that may be used to grow energy crops [3]. We selected six land cover types as the available marginal land for growing the energy plants in compliance with the principle that bioenergy development should not compete with cropland and ecologically protected land. These six types were "mosaic vegetation (grassland/shrub land/forest) (50-70\%)/cropland (20-50\%)," "sparse (<15\%) vegetation," "mosaic grassland (50-70\%)/forest or shrub land (20-50\%)," "closed to open $(>15 \%)$ (broad-leaved or needle-leaved and evergreen or deciduous) shrub land $(<5 \mathrm{~m})$," "closed to open $(>15 \%)$ grassland or woody vegetation on regularly flooded or waterlogged soil," and "bare areas." The selection of land cover types for each country can be flexible based on the law, policy, environmental conditions, and special regulations. For example, nature reserves should be excluded in further studies.

2.3. Characteristics of Selected Energy Plants. Cassava, as feedstock for fuel ethanol, has three advantages over others. First, Cassava is a shrubby tropical plant, widely grown for its large, tuberous, starchy roots, especially on marginal land. Second, Cassava is not a staple food for most people in Asia. Third, it is easy to comminute, has short cooking times, and has a low gelatinization temperature. Therefore, Cassava is a suitable feedstock for fuel ethanol $[33,57]$.

$P$. chinensis is an ideal species for producing biodiesel. The tree has several outstanding characteristics: drought resistance, tolerance to cold climate, and tolerance to poor, acid, or alkaline soils. It also has some advantages that cannot be replaced by other trees, such as oil yield and its conversion rate, biodiesel quality, geographical distribution, adaptability, and economic benefits cycle. Therefore, $P$. chinensis is considered an important source of biodiesel $[34,47,52]$.
JCL is a famous biofuel plant and has been studied globally $[31,58]$. It is a tropical species, native to Mexico and Central America, but is widely distributed in wild or semicultivated stands in Latin America, Africa, India, and South-East Asia [59]. The Jatropha curcas plant is a nonedible, drought-resistant, perennial plant that has the capability to grow on marginal lands because it requires very few nutrients to survive [34, 44]. Jatropha has several other advantages, such as a short gestation period, resistance to common pests, lack of consumption by cattle, and production of biofertilizer and glycerine as useful by-products of biodiesel. In addition, the seed collection period of Jatropha does not coincide with the rainy season in June and July, which is when most agricultural activities take place. This makes it possible for people to generate additional income during the slack agricultural season $[60,61]$.

All the specific requirements of the energy plants were chosen according to the literature and advice from experts. The growing conditions of the energy plants are listed in Table 2 . The marginal land presented in the previous section was used as the basic condition in the multiple factor analysis.

We used strict criteria during the identification of suitable and moderately suitable areas for energy plants. Marginal land resource areas were only characterized as suitable if all of the suitable conditions were met. If one of the growing conditions was moderately suitable, the land resources were identified as moderately suitable.

The soil texture data used in this paper was classified into two classes. Class 1 was defined as fine textured with more than $35 \%$ clay. Class 2 was defined as medium textured with a clay percentage between $18 \%$ and $35 \%$. The soil texture requirement of energy plants is that the volumetric ratio of clay should be more than 30\% for suitable land and 18\% 35\% for moderately suitable land. Therefore, there may be more 


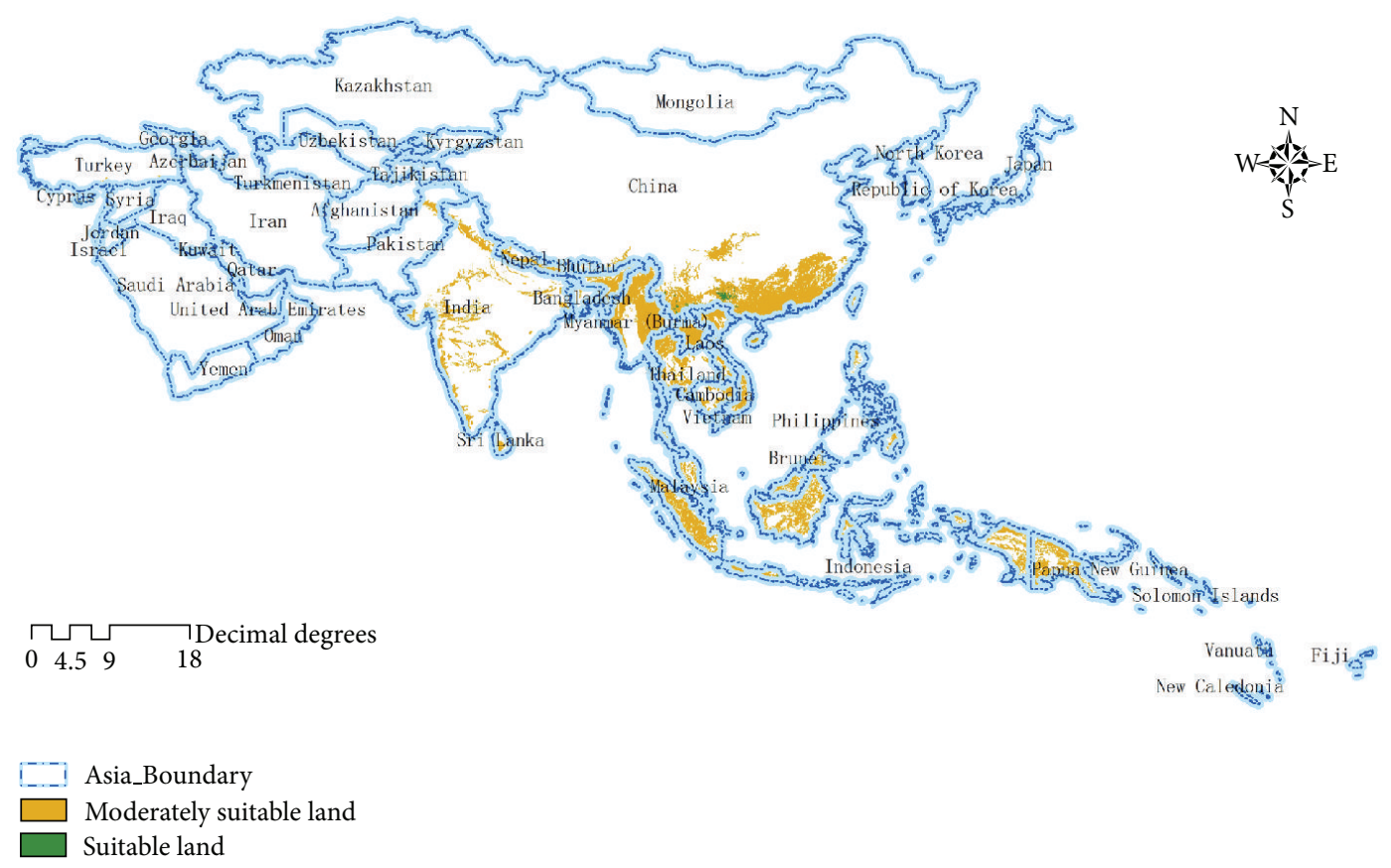

(a) Spatial distribution

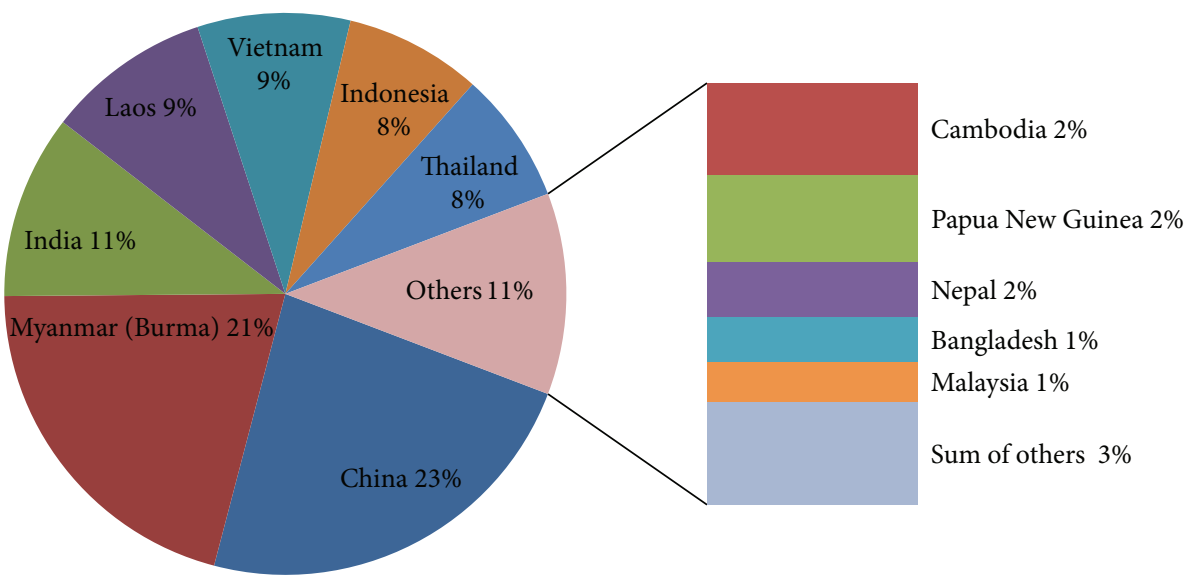

(b) Distribution in different countries

FIGURE 2: Distribution of marginal land resources for Cassava.

potential land resource areas available for growing energy plants if more accurate soil data can be obtained.

\section{Results and Discussion}

The planting zones of each energy plant were identified based on marginal land areas and the plant's growth habits. The multiple factor analysis method was adopted to evaluate the suitable marginal land resources based on the evaluation criteria for suitable and moderately suitable growing conditions of each single factor and the type of available land cover. The distributions of marginal land resources suitable for the three energy plants are presented in Figures 2, 3, and 4.
From the figures above, we can see that the area suitable for the growth of $P$. chinensis is much larger than those for the other two plants. Approximately 70\% of Asian countries have more than one thousand square kilometers of marginal land resources suitable for $P$. chinensis. Cassava and JCL resources are limited because they require warmer temperatures than P. chinensis, and Cassava has a higher precipitation requirement. The results in Table 3 show that the areas of marginal land resources of Cassava, P. chinensis, and JCL are nearly 1.12 million, 2.41 million, and 237 thousand square kilometers, respectively. China has the most marginal land area available for all of the energy plants. Myanmar possesses $21 \%$ of the land resources suitable for Cassava. Turkey and Thailand have the second largest marginal land resources suitable for $P$. 


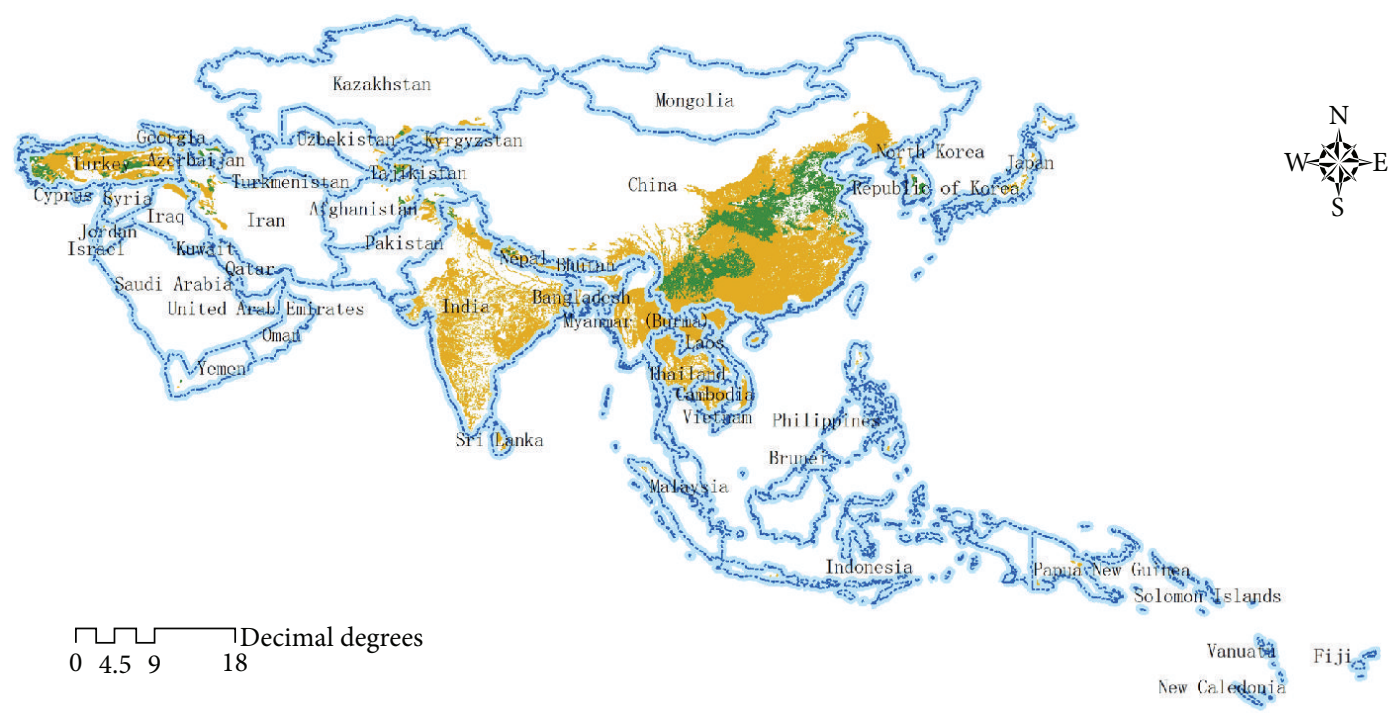

Asia_Boundary

$\square$ Moderately suitable land

Suitable land

(a) Spatial distribution

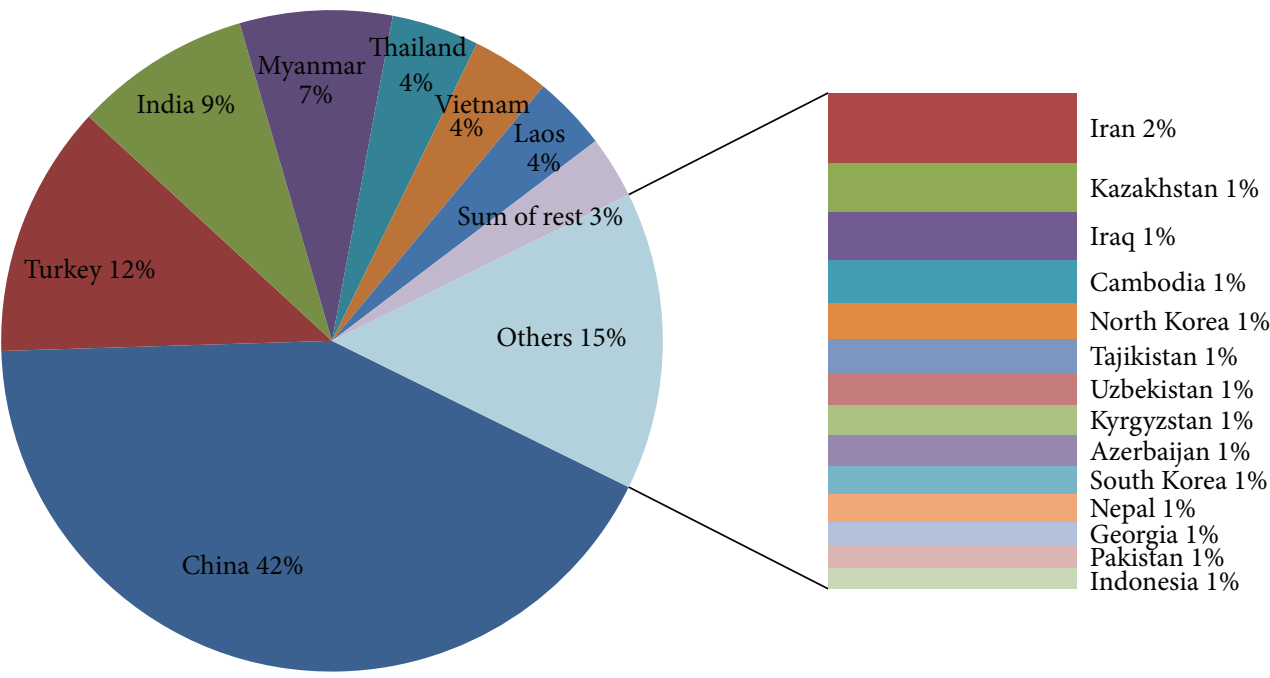

(b) Distribution in different countries

Figure 3: Distribution of marginal land resources for P. chinensis.

TABLE 3: Marginal land resources suitable and moderately suitable for Cassava, $P$. chinensis, and JCL planting based on multiple factor analysis in Asia $\left(\mathrm{km}^{2}\right)$.

\begin{tabular}{|c|c|c|c|c|c|c|c|c|}
\hline \multirow{2}{*}{ Land cover } & \multicolumn{2}{|c|}{ Cassava } & \multicolumn{2}{|c|}{ P. chinensis } & \multicolumn{2}{|c|}{$J C L$} & \multicolumn{2}{|c|}{ Total } \\
\hline & $S$ & M & S & M & $S$ & M & S & M \\
\hline Mosaic vegetation & 1422 & 307537 & 130443 & 769321 & 1 & 92458 & 131866 & 1169316 \\
\hline Mosaic grassland & 4 & 3697 & 17223 & 73886 & 0 & 2461 & 17227 & 80044 \\
\hline Shrub land & 2089 & 788006 & 73008 & 942428 & 2 & 123672 & 75099 & 1854106 \\
\hline Herbaceous vegetation & 6 & 16928 & 9221 & 89459 & 0 & 8794 & 9227 & 115181 \\
\hline Sparse vegetation & 0 & 684 & 28002 & 180892 & 0 & 5732 & 28002 & 187308 \\
\hline Bare areas & 0 & 3572 & 7529 & 88703 & 0 & 4530 & 7529 & 96805 \\
\hline Total & 3521 & 1120424 & 265426 & 2144689 & 3 & 237647 & 268950 & 3502760 \\
\hline
\end{tabular}

S: suitable land; M: moderately suitable land. 


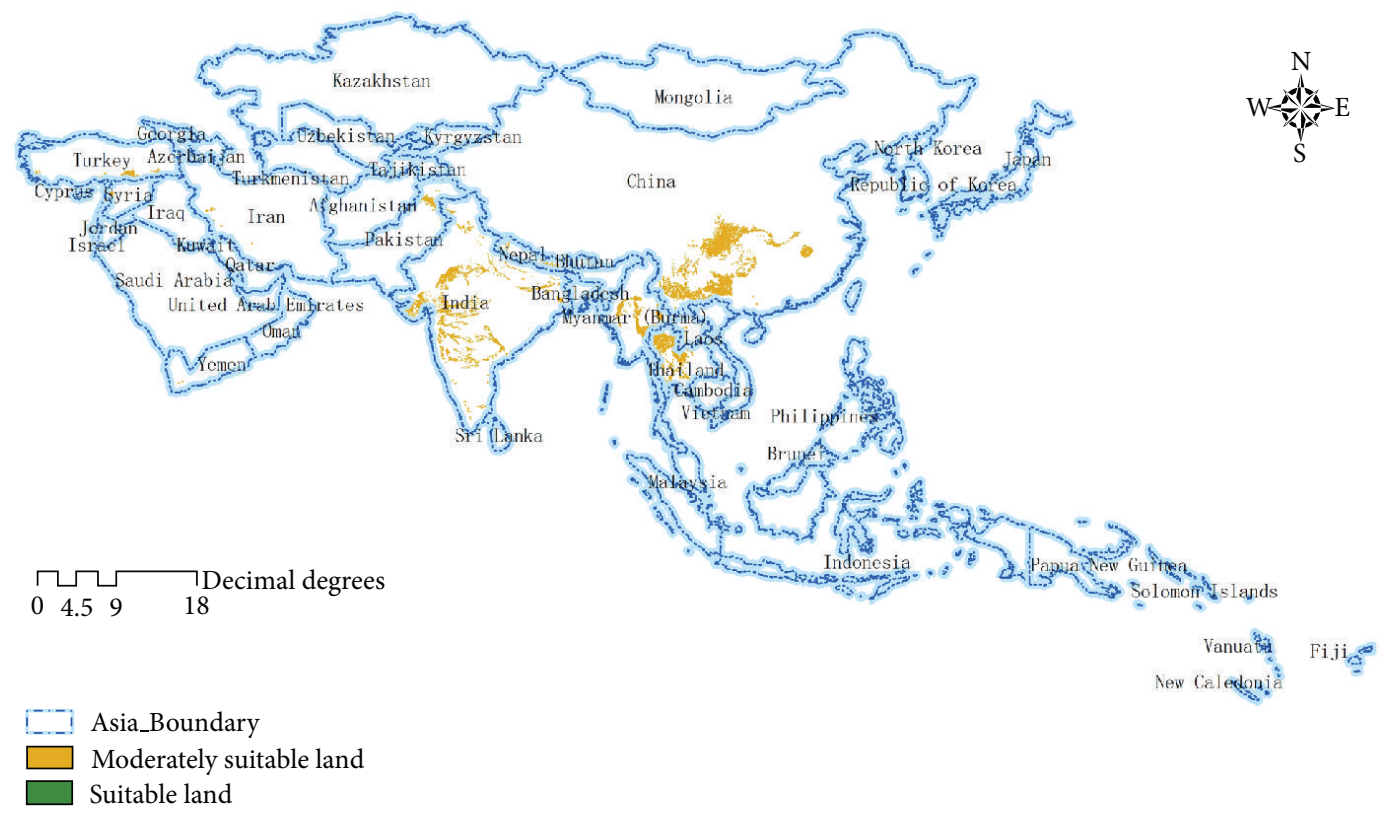

(a) Spatial distribution

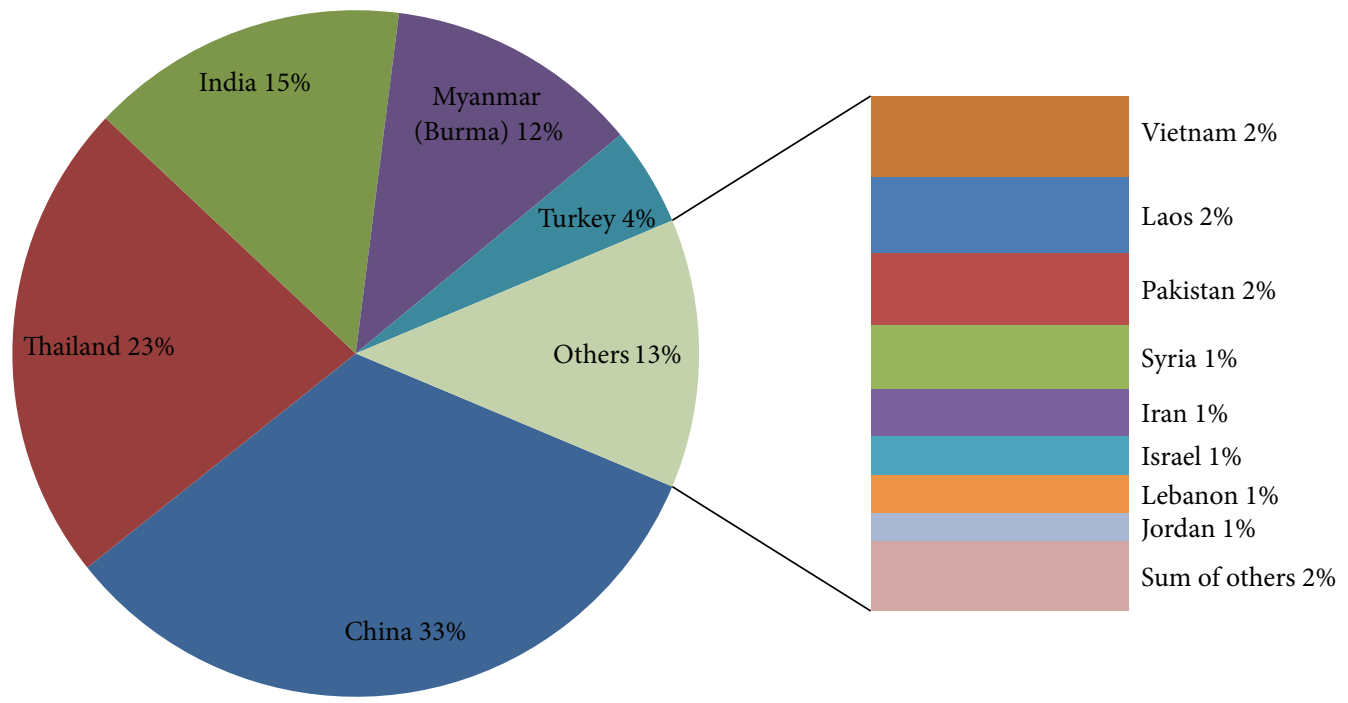

(b) Distribution in different countries

FIGURE 4: Distribution of marginal land resources for JCL.

chinensis and JCL. Shrub land is the dominant land cover type for growing energy plants, which accounts for $51.14 \%$ of the total suitable area. Mosaic vegetation is next, accounting for $34.49 \%$.

\section{Conclusion}

In this paper, a multiple factor analysis method was adopted to identify marginal land resources for three types of energy plants (Cassava, P. chinensis, and JCL) in Asia based on land cover, meteorological data, soil characteristics, terrain data, and the growth habits of energy plants. GIS was used to identify potential land resource areas at the resolution of 1 square kilometer. The conclusions of this study are as follows.

(1) The areas of marginal land suitable for Cassava, $P$. chinensis, and JCL were established to be 1.12 million, 2.41 million, and 0.237 million $\mathrm{km}^{2}$, respectively. The policy and environmental constraints of each specific county were not considered in this study.

(2) China has great prospects for bioenergy development. It has the most marginal land resources available for all three energy plants. Myanmar, Turkey, and Thailand have the second largest areas of marginal 
land resources available for Cassava, $P$. chinensis, and $J C L$, respectively.

(3) With regard to land cover, shrub land is the dominant land cover type for growing energy plants, accounting for $51.14 \%$ of the total suitable area. Mosaic vegetation is second, accounting for $34.49 \%$.

Bioenergy development is important and full of challenges. Further research needs to be performed to choose the best feedstock, improve marginal land resource calculations using more accurate input data, estimate the energy production potential, and analyze the environmental effects coupled with social and economic benefits.

\section{Conflict of Interests}

The authors declare that there is no conflict of interests regarding the publication of this paper.

\section{Acknowledgments}

Two anonymous referees and the editor of this paper are thanked for their suggestions for the improvement of the paper. The study was supported by the Chinese Academy of Sciences (Grant no. KZZD-EW-08) and the High Resolution Earth Observation Systems of National Science and Technology Major Projects (05-Y30B02-9001-13/15-10).

\section{References}

[1] BP Statistical Review of World Energy, 2012.

[2] A. Karp and I. Shield, "Bioenergy from plants and the sustainable yield challenge," New Phytologist, vol. 179, no. 1, pp. 15-32, 2008.

[3] Y. Tang, J.-S. Xie, and S. Geng, "Marginal land-based biomass energy production in China," Journal of Integrative Plant Biology, vol. 52, no. 1, pp. 112-121, 2010.

[4] J. Zhuang, R. W. Gentry, G.-R. Yu, G. S. Sayler, and J. W. Bickham, "Bioenergy sustainability in China: potential and impacts," Environmental management, vol. 46, no. 4, pp. 525$530,2010$.

[5] J. Hill, E. Nelson, D. Tilman, S. Polasky, and D. Tiffany, "Environmental, economic, and energetic costs and benefits of biodiesel and ethanol biofuels," Proceedings of the National Academy of Sciences of the United States of America, vol. 103, no. 30, pp. 11206-11210, 2006.

[6] P. R. Adler, S. J. del Grosso, and W. J. Parton, "Life-cycle assessment of net greenhouse-gas flux for bioenergy cropping systems," Ecological Applications, vol. 17, no. 3, pp. 675-691, 2007.

[7] A. L. Stephenson, J. S. Dennis, and S. A. Scott, "Improving the sustainability of the production of biodiesel from oilseed rape in the UK," Process Safety and Environmental Protection, vol. 86, no. 6, pp. 427-440, 2008.

[8] REN21 Renewables 2012 Global Status Report. Renewable Energy Policy Network for the 21st Century, 2012.

[9] ExxonMobil, The Outlook for Energy: A View to 2040, 2013.

[10] M. M. Mochizuki, A. Tellis, and M. Wills, Confronting Terrorism in the Pursuit of Power: Strategic Asia, 2004-2005, 2004.
[11] S. Kumar, P. Abdul Salam, P. Shrestha, and E. K. Ackom, "An assessment of Thailand's biofuel development," Sustainability, vol. 5, no. 4, pp. 1577-1597, 2013.

[12] A. Thomas, A. Bond, and K. Hiscock, "A GIS based assessment of bioenergy potential in England within existing energy systems," Biomass \& Bioenergy, vol. 55, pp. 107-121, 2013.

[13] I. Gelfand, R. Sahajpal, X. Zhang, R. C. Izaurralde, K. L. Gross, and G. P. Robertson, "Sustainable bioenergy production from marginal lands in the US Midwest," Nature, vol. 493, no. 7433, pp. 514-517, 2013.

[14] S. Liang, M. Xu, and T. Z. Zhang, "Life cycle assessment of biodiesel production in China," Bioresource Technology, vol. 129, pp. 72-77, 2013.

[15] Y. P. Wu, S. G. Liu, and Z. P. Li, "Identifying potential areas for biofuel production and evaluating the environmental effects: a case study of the James River Basin in the Midwestern United States," Global Change Biology Bioenergy, vol. 4, no. 6, pp. 875888, 2012.

[16] A. L. Borrion, M. C. McManus, and G. P. Hammond, "Environmental life cycle assessment of lignocellulosic conversion to ethanol: a review," Renewable \& Sustainable Energy Reviews, vol. 16, no. 7, pp. 4638-4650, 2012.

[17] P. Schröder, R. Herzig, B. Bojinov et al., "Bioenergy to save the world: producing novel energy plants for growth on abandoned land," Environmental Science and Pollution Research, vol. 15, no. 3, pp. 196-204, 2008.

[18] B. Batidzirai, E. M. W. Smeets, and A. P. C. Faaij, "Harmonising bioenergy resource potentials-methodological lessons from review of state of the art bioenergy potential assessments," Renewable \& Sustainable Energy Reviews, vol. 16, no. 9, pp. 6598-6630, 2012.

[19] T. Hattori and S. Morita, "Energy crops for sustainable bioethanol production; which, where and how?" Plant Production Science, vol. 13, no. 3, pp. 221-234, 2010.

[20] Q. Zhang, J. Ma, G. Qiu et al., "Potential energy production from algae on marginal land in China," Bioresource Technology, vol. 109, pp. 252-260, 2012.

[21] H. Qiu, J. Huang, M. Keyzer et al., "Biofuel development, food security and the use of marginal land in china," Journal of Environmental Quality, vol. 40, no. 4, pp. 1058-1067, 2011.

[22] D. Zhuang, D. Jiang, L. Liu, and Y. Huang, "Assessment of bioenergy potential on marginal land in China," Renewable \& Sustainable Energy Reviews, vol. 15, no. 2, pp. 1050-1056, 2011.

[23] Y.-K. Tseng, "The economical and environmental advantages of growing Jatropha curcas on marginal land," Advanced Materials Research, vol. 361-363, pp. 1495-1498, 2012.

[24] Z.-C. Li and X.-M. Liang, "Analysis of the potential of cassava used as raw materials for fuel alcohol production in China," Liquor-Making Science \& Technology, vol. 4, pp. 31-33, 2010.

[25] C. Jansson, A. Westerbergh, J. Zhang, X. Hu, and C. Sun, "Cassava, a potential biofuel crop in China," Applied Energy, vol. 86, no. 1, pp. S95-S99, 2009.

[26] C. Sorapipatana and S. Yoosin, "Life cycle cost of ethanol production from cassava in Thailand," Renewable \& Sustainable Energy Reviews, vol. 15, no. 2, pp. 1343-1349, 2011.

[27] K. Sriroth, K. Piyachomkwan, S. Wanlapatit, and S. Nivitchanyong, "The promise of a technology revolution in cassava bioethanol: from Thai practice to the world practice," Fuel, vol. 89, no. 7, pp. 1333-1338, 2010.

[28] S. Kumar, J. Singh, S. M. Nanoti, and M. O. Garg, "A comprehensive Life Cycle Assessment (LCA) of Jatropha biodiesel 
production in India," Bioresource Technology, vol. 110, pp. 723729, 2012.

[29] Y.-K. Tseng, "The economical and environmental advantages of growing Jatropha curcas on marginal land," Advanced Materials Research, vol. 361-363, pp. 1495-1498, 2012.

[30] H. C. Ong, T. M. I. Mahlia, H. H. Masjuki, and R. S. Norhasyima, "Comparison of palm oil, Jatropha curcas and Calophyllum inophyllum for biodiesel: a review," Renewable \& Sustainable Energy Reviews, vol. 15, no. 8, pp. 3501-3515, 2011.

[31] K. Openshaw, "A review of Jatropha curcas: an oil plant of unfulfilled promise," Biomass and Bioenergy, vol. 19, no. 1, pp. $1-15,2000$.

[32] L. Axelsson, M. Franzén, M. Ostwald, G. Berndes, G. Lakshmi, and N. H. Ravindranath, "Jatropha cultivation in southern India: assessing farmers' experiences," Biofuels, Bioproducts and Biorefining, vol. 6, no. 3, pp. 246-256, 2012.

[33] D. Zhuang, D. Jiang, L. Liu, and Y. Huang, "Assessment of bioenergy potential on marginal land in China," Renewable \& Sustainable Energy Reviews, vol. 15, no. 2, pp. 1050-1056, 2011.

[34] M. Tang, P. Zhang, L. Zhang, M. Li, and L. Wu, "A potential bioenergy tree: Pistacia chinensis Bunge," in Proceedings of the International Conference on Future Energy, Environment, and Materials B, G. Yang, Ed., pp. 737-746, 2012.

[35] B. Antizar-Ladislao and J. L. Turrion-Gomez, "Secondgeneration biofuels and local bioenergy systems," Biofuels, Bioproducts and Biorefining, vol. 2, no. 5, pp. 455-469, 2008.

[36] A. K. Chandel, E. C. Chan, R. Rudravaram, M. L. Narasu, L. V. Rao, and P. Ravinda, "Economics and environmental impact of bioethanol production technologies: an appraisal," Biotechnology and Molecular Biology Review, vol. 2, no. 1, pp. 14-32, 2007.

[37] H. Shao and L. Chu, "Resource evaluation of typical energy plants and possible functional zone planning in China," Biomass and Bioenergy, vol. 32, no. 4, pp. 283-288, 2008.

[38] C. Zhang, W. Han, X. Jing, G. Pu, and C. Wang, "Life cycle economic analysis of fuel ethanol derived from cassava in southwest China," Renewable \& Sustainable Energy Reviews, vol. 7, no. 4, pp. 353-366, 2003.

[39] E. Nuwamanya, L. Chiwona-Karltun, R. S. Kawuki, and Y. Baguma, "Bio-ethanol production from non-food parts of cassava (Manihot esculenta Crantz)," Ambio, vol. 41, no. 3, pp. 262-270, 2012.

[40] T. Silalertruksa and S. H. Gheewala, "Security of feedstocks supply for future bio-ethanol production in Thailand," Energy Policy, vol. 38, no. 11, pp. 7476-7486, 2010.

[41] R. Sarin, M. Sharma, S. Sinharay, and R. K. Malhotra, "Jatrophapalm biodiesel blends: an optimum mix for Asia," Fuel, vol. 86, no. 10-11, pp. 1365-1371, 2007.

[42] S. Jain and M. P. Sharma, "Prospects of biodiesel from Jatropha in India: a review," Renewable \& Sustainable Energy Reviews, vol. 14, no. 2, pp. 763-771, 2010.

[43] R. Abdulla, E. S. Chan, and P. Ravindra, "Biodiesel production from Jatropha curcas: a critical review," Critical Reviews in Biotechnology, vol. 31, no. 1, pp. 53-64, 2011.

[44] C.-Y. Yang, Z. Fang, B. Li, and Y.-F. Long, "Review and prospects of Jatropha biodiesel industry in China," Renewable \& Sustainable Energy Reviews, vol. 16, no. 4, pp. 2178-2190, 2012.

[45] M. A. Kalam, J. U. Ahamed, and H. H. Masjuki, "Land availability of Jatropha production in Malaysia," Renewable \& Sustainable Energy Reviews, vol. 16, no. 6, pp. 3999-4007, 2012.
[46] M. H. Chakrabarti, M. Ali, J. N. Usmani et al., "Status of biodiesel research and development in Pakistan," Renewable \& Sustainable Energy Reviews, vol. 16, no. 7, pp. 4396-4405, 2012.

[47] L. Lu, D. Jiang, D. Zhuang, and Y. Huang, "Evaluating the marginal land resources suitable for developing pistacia chinensis-based biodiesel in China," Energies, vol. 5, no. 7, pp. 2165-2177, 2012.

[48] S. Bontemps, P. Defourny, E. van Bogaert et al., GlobCover 2009, vol. 53, European Spatial Agency-Université Catholique de Louvain, 2011.

[49] A. Jarvis, H. I. Reuter, A. Nelson, and E. Guevara, "Hole-filled SRTM for the globe version 4," The CGIAR-CSI SRTM 90m Database, 2008, http://www.cgiar-csi.org.

[50] R. J. Hijmans, S. E. Cameron, J. L. Parra, P. G. Jones, and A. Jarvis, "Very high resolution interpolated climate surfaces for global land areas," International Journal of Climatology, vol. 25, no. 15, pp. 1965-1978, 2005.

[51] FAO/IIASA/ISRIC/ISS-CAS/JRC Harmonized World Soil Database (Version 1.1), 2009.

[52] X. Hou, H. Zuo, and H. Mou, "Geographical distribution of energy plant Pistacia chinensis Bunge in China," Ecology and Environmental Sciences, vol. 19, pp. 1160-1164, 2010.

[53] Y. Fu, X. Pan, and H. Gao, "Geographical distribution and climate characteristics of habitat of Pistacia chinensis Bunge in China," Chinese Journal of Agrometeorology, vol. 30, no. 3, pp. 318-322, 2009.

[54] J. Heller, Physic Nut, Jatropha curcas L., vol. 1, Bioversity International, 1996.

[55] R. K. Henning, "Jatropha curcas L," Plant Resources of the Tropical Africa, vol. 14, pp. 116-122, 2004.

[56] K. Eckart and P. Henshaw, "Jatropha curcas L. and multifunctional platforms for the development of rural sub-Saharan Africa," Energy for Sustainable Development, vol. 16, no. 3, pp. 303-311, 2012.

[57] H. Yang, L. Chen, Z. Yan, and H. Wang, "Emergy analysis of cassava-based fuel ethanol in China," Biomass and Bioenergy, vol. 35, no. 1, pp. 581-589, 2011.

[58] N. Foidl, G. Foidl, M. Sanchez, M. Mittelbach, and S. Hackel, "Jatropha curcas L. as a source for the production of biofuel in Nicaragua," Bioresource Technology, vol. 58, no. 1, pp. 77-82, 1996.

[59] V. C. Pandey, K. Singh, J. S. Singh, A. Kumar, B. Singh, and R. P. Singh, "Jatropha curcas: a potential biofuel plant for sustainable environmental development," Renewable \& Sustainable Energy Reviews, vol. 16, no. 5, pp. 2870-2883, 2012.

[60] S. Kumar, A. Chaube, and S. K. Jain, "Sustainability issues for promotion of Jatropha biodiesel in Indian scenario: a review," Renewable \& Sustainable Energy Reviews, vol. 16, no. 2, pp. 10891098, 2012.

[61] P. Kumar Biswas, S. Pohit, and R. Kumar, "Biodiesel from jatropha: can India meet the 20\% blending target?" Energy Policy, vol. 38, no. 3, pp. 1477-1484, 2010. 

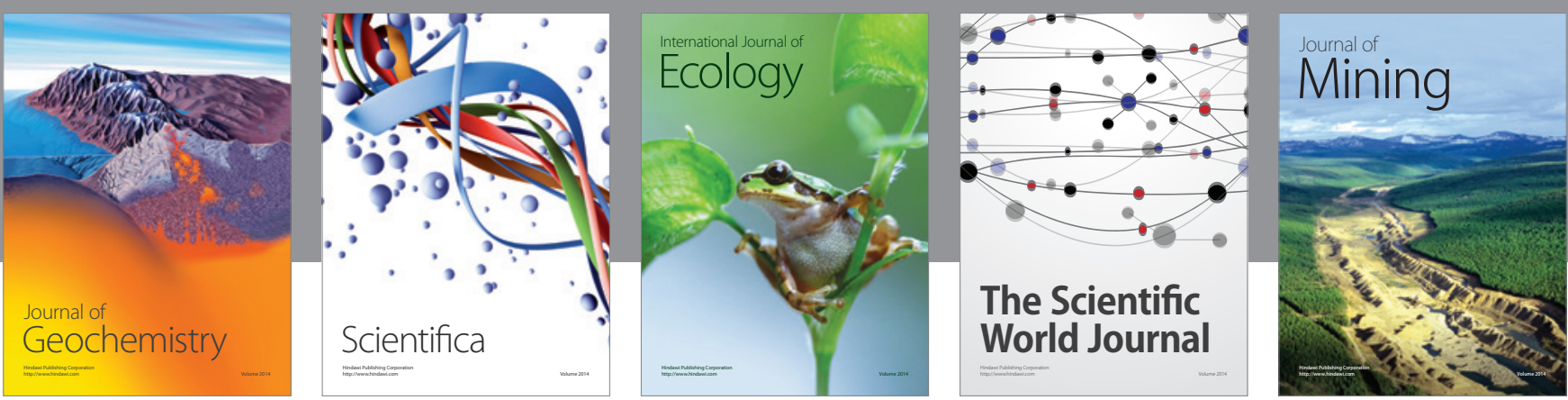

The Scientific World Journal
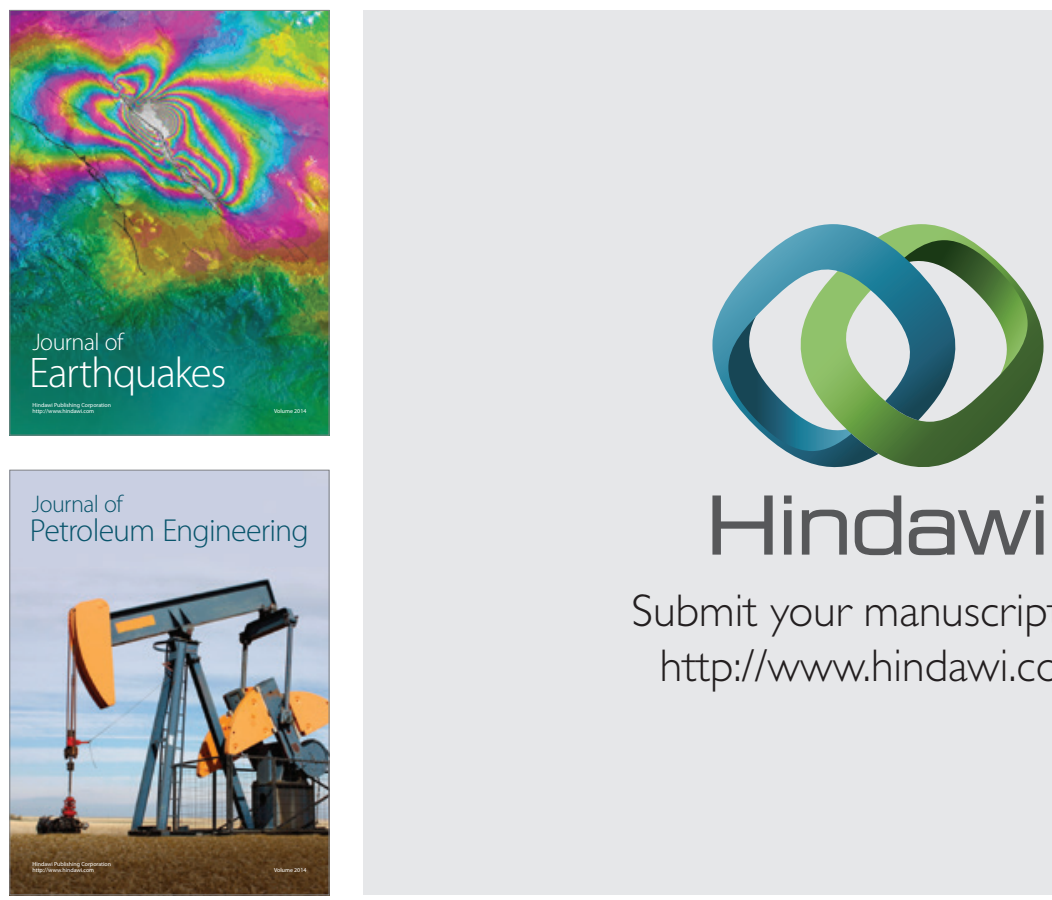

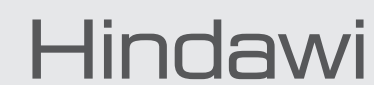

Submit your manuscripts at

http://www.hindawi.com
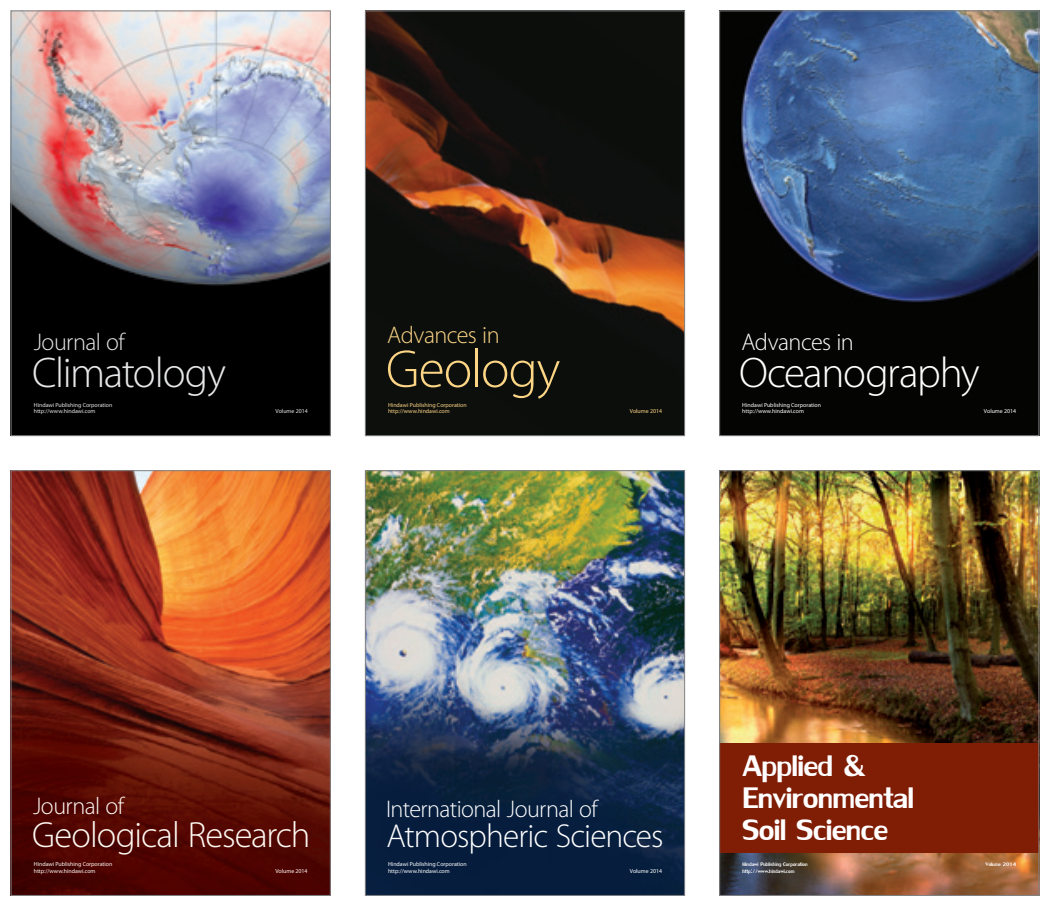
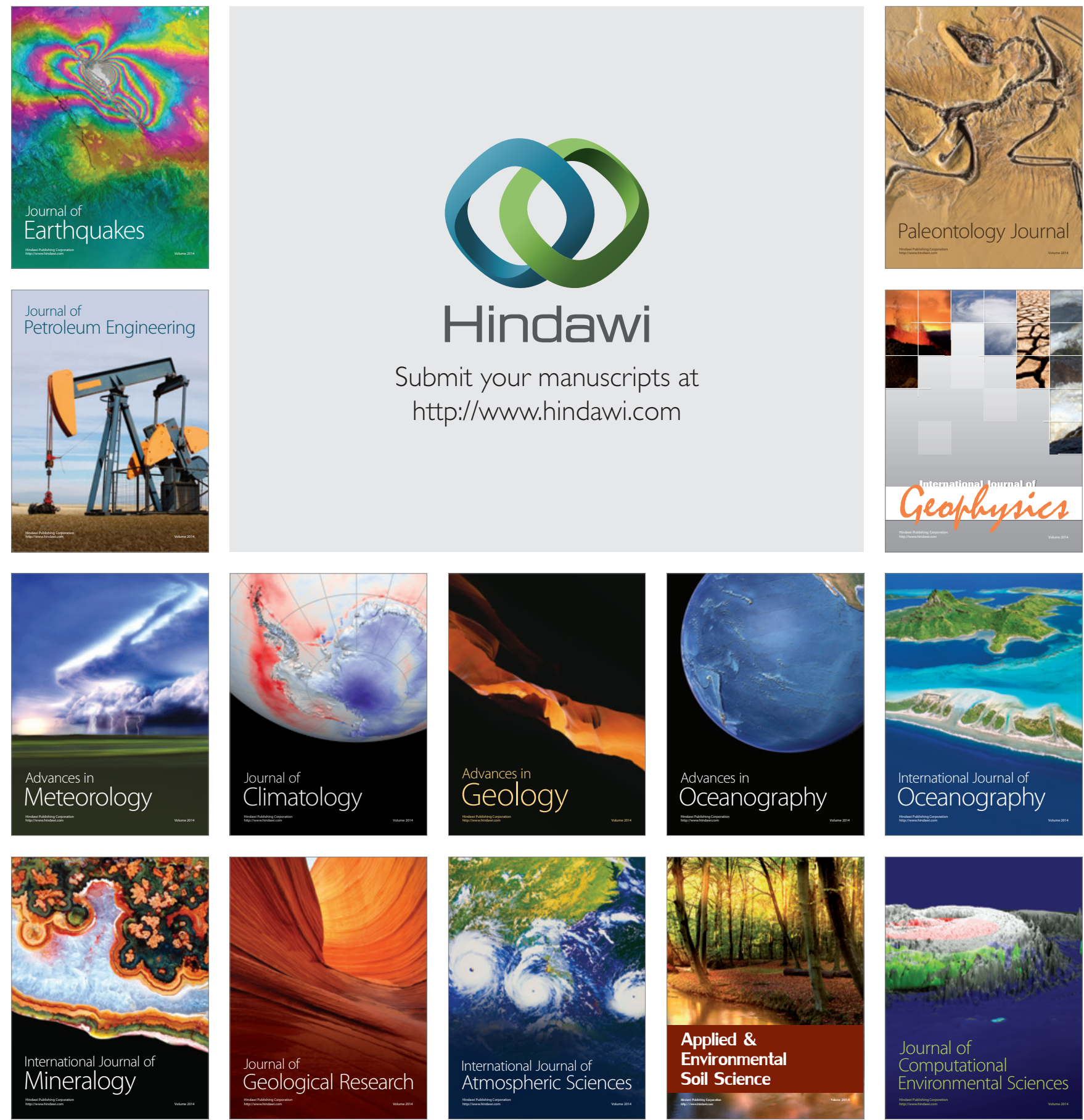